\title{
ARTICLE
}

\section{SELECTION OF CULTURE MEDIA FOR THE PRODUCTION OF CAROTENOIDS WITH ANTIOXIDANT ACTIVITY BY RHODOTORULA GLUTINIS}

\author{
Gerelmaa Z. ${ }^{1 *}$, Zultsetseg Ch. ${ }^{1}$, Batjargal B. ${ }^{2}$ and Rentsenkhand Ts. ${ }^{1}$ \\ ${ }^{1}$ Laboratory of Microbial Synthesis, Institute of General and Experimental Biology, \\ Mongolian Academy of Sciences, Ulaanbaatar, Mongolia \\ ${ }^{2}$ Department of Biology, School of Arts and Sciences, \\ National University of Mongolia, Ulaanbaatar, Mongolia
}

ARTICLE INFO: Received: 24 Oct, 2018; Accepted: 21 Dec, 2018

\begin{abstract}
Rhodotorula glutinis is an aerobic yeast with particular metabolic characteristic that can produce large amount of carotenoids during the stationary growth phase. Carotenoid is an important natural pigment with antioxidant properties, which is used in food, pharmaceutical and cosmetics industry as additives. The aim of this work is to study the production of carotenoid with antioxidant activity by R.glutinis R12 in different media conditions. The selected strain was cultivated in three different culture media such as YM broth, Basal and MS3 medium at $28^{\circ} \mathrm{C}$ for $72-120$ hours. After fermentation, cells were harvested by centrifugation and freeze-dried. Carotenoid from the biomass was extracted as a mixture of DMSO, acetone and petroleum ether with a ratio of 1:2:2 and cells were ruptured using ultrasonic wave. The carotenoid content in the supernatant was measured by spectrophotometric method. The highest content of carotenoids extracted from R.glutinis $R 12$ was $283.71 \mu \mathrm{g} / \mathrm{g}$ dry biomass. The maximum antioxidant activity of carotenoid by DPPH assays were achieved $52.09 \pm 0.4 \%\left(I C_{50}=536.02\right)$ and at a concentration of $600 \mu \mathrm{g} \mathrm{ml}-1$. This study revealed that the R.glutinis R12 strain has the ability to produce carotenoid and has shown antioxidant activity in Basal and MS3 medium. For further study, it is necessary to investigate the improvement of carotenoid yield from R.glutinis R12 strains.
\end{abstract}

Keywords: Rhodotorula glutinis; carotenoids; antioxidant activity; culture media;

\section{INTRODUCTION}

Rhodotorula which belongs to includes three active species; Rhodotorula Basidiomycota phylum; Urediniomycetes class and Sporidial order are the main carotenoid producing microorganisms with predominant synthesis of $\beta$-carotene, torulene and torularodin [18]. The genus Rhodotorula glutinis, Rhodotorula minuta and Rhodotorula mucilaginosa (formerly known as Rhodotorula rubra) [14]. R.glutinis often called "pink yeast" is a free living, non-fermenting, unicellular yeast found commonly in nature and is 
particularly important for food industries because of their biotechnological potential and safety implications. Moreover, they are widely known as a good source of proteins, lipids and vitamins [23].

Carotenoid pigments represent the largest and most diverse class of natural products known to mankind. Nowadays, over 700 structures have been reported [5] and they are natural pigments that can be synthesized by various microorganisms, including bacteria, yeasts, filamentous fungi [3] and microalgae [12]. Carotenoids are derived from isoprene, formed by forty carbon chains whose main characteristic is the presence of a long chain polyene (where the presence of double bonds can range from three to fifteen) responsible for the color perceived by the human eye. Carotenoids represent a group of valuable molecules for the pharmaceuticals, medicine, cosmetics, food and feed industries, not only because they can act as vitamin A precursors, but also for their coloring, antioxidant, and possible tumor-inhibiting activity, and also, enhancement of the immune response leading to protection against bacterial and fungal infections [17], [13]. Moreover, Carotenoids may serve as a protection against many chronic diseases such as cancer, age-related Macular Degeneration, and cardiovascular diseases and also act as an excellent antioxidant system within cells [27]. Interest in carotenoids has recently increased due to the growing

\section{MATERIALS AND METHODS}

Yeast strain: Rhodotorula glutinis R12 strain was supplied from the Culture Collection of the Laboratory of Microbial Synthesis, Institute of General and Experimental Biology, Mongolian Academy of Sciences.

Media: YM broth (10g glucose, $5 \mathrm{~g}$ peptone, $3 \mathrm{~g}$ yeast extract and $3 \mathrm{~g}$ malt extract per liter), Basal medium (20g glucose, $4 \mathrm{~g}$ yeast

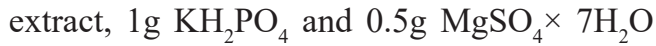
per liter) and MS3 medium (30g glucose, $1.5 \mathrm{~g}$ yeast extract, $5 \mathrm{~g} \mathrm{NH} \mathrm{NO}_{3}, 1 \mathrm{~g} \mathrm{K \textrm {K } _ { 2 }} \mathrm{PO}_{4}$, demand for such compounds in many similar industries [28]. The global market demand for carotenoids grows $2.9 \%$ per year, with estimated annual sales of about US\$300 million in synthetic carotenoids [11], [29]. The global carotenoids market was estimated to be valued at USD1.24 billion in 2016 and projected to reach USD1.53 Billion by 2021, at a CAGR of $3.78 \%$ from 2016 to 2021 .

Commercial production of carotenoids from microorganisms competes mainly with synthetic production by chemical procedures. Carotenoids used industrially are mainly obtained chemically or by extraction of plants or algae. However, due to the concern about the use of chemical additives in foods, there is increasing interest in carotenoids obtained naturally through biotechnological processes and the microbial carotenoids have attracted much attention in recent years [25]. Therefore, the yeast stands out as a natural source of carotenoids.

Rhodotorula mucilaginosa, Rhodotorula slooffiae and Rhodotorula glutinis strains were previously isolated from fruits, soil and insects in Mongolia [2], [22], [25].

But there are not studies and reports on antioxidant activity of carotenoid pigment extracted from Rhodotorula strains isolated from Mongolia. Therefore, we aimed to study carotenoid producing Rhodotorula glutinis R12 with antioxidant activity.

$0.4 \mathrm{~g} \mathrm{MgSO}_{4} \times 7 \quad \mathrm{H}_{2} \mathrm{O}, \quad 0.4 \mathrm{~g} \quad \mathrm{NaCl}$ and $0.4 \mathrm{~g}$ L-alanine per liter) were used for the cultivation. YM agar, Yeast morphology agar, Yeast Nitrogen base, Yeast Carbon base and Vitamin free medium were used to verify the morphological, physiological and biochemical characteristics

Morphological, physiological and biochemical characterization: Morphological characteristics of the cultures such as shape, cellular dimension and type of cell division 
were examined by microscopic analysis of the strain grown in YM broth and colony characteristics were observed through culture grown in Yeast morphology agar medium at $28^{\circ} \mathrm{C}$ for 24 hours. After the determination of the morphological characteristics, tests were carried out to verify the principal physiological and biochemical characteristics, according to Barnett et al., 1990.

Inoculum: A single colony from the stock culture on YM agar was transferred to $50 \mathrm{ml}$ of YM broth and incubated in a shaker at $150 \mathrm{rpm}$, at $28^{\circ} \mathrm{C}$ for an overnight period. The cells in the medium were counted by microscopy in a Fuchs - Rosenthal chamber (Blaubrand, Germany).

Cultivation: The inoculum $\left(10^{8}\right.$ cells/ $\mathrm{ml})$ were inoculated with $5 \%(\mathrm{v} / \mathrm{v})$ in $500 \mathrm{ml}$ Erlenmeyer flask containing $100 \mathrm{~mL}$ of YM broth, Basal medium and MS3 medium respectively and then incubated in a rotary shaker at $150 \mathrm{rpm}, 28^{\circ} \mathrm{C}$ for 72,96 and 120 hours respectively.

Determination of dry cell biomass: $100 \mathrm{ml}$ of yeast suspension was centrifuged for 20 minutes at $3000 \mathrm{rpm}$, washed twice with distilled water, and again centrifuged under same condition. Then the pellet was dried in freeze-dryer (BK - FD18PT, Biobase Biodustry, Shandong, China). Cell biomass was measured by the dry cell weight method [15].

Cell disruption technique: The combination method for cell disruption was used: chemical disruption with DMSO (dimethyl sulfioxide) and ultrasonic wave used as mechanical technique. $1 \mathrm{ml}$ DMSO was added in $0.01 \mathrm{~g}$ dried yeast biomass and this mixture was stood for one hour and $2 \mathrm{ml}$ of acetone added. The mixture was homogenized at $40 \mathrm{kHz}$ for $20 \mathrm{~min}$ by using ultrasonic (08895-51 ultrasonic bath, Cole - Parmer Instrument company, Vernon Hills, USA). After the disruption, $2 \mathrm{ml}$ of petroleum ether was added to the mixture [20].
Extraction and determination of pigment: To extract carotenoid from the cells were used a solvent mixture of DMSO, acetone and petroleum ether. $1 \mathrm{ml}$ of DMSO and $2 \mathrm{ml}$ of acetone and $2 \mathrm{ml}$ of petroleum ether was added in $0.01 \mathrm{~g}$ cell dry biomass separately. The yeast cells were disrupted by ultrasonic wave. Upon standing for 25-30 min, the extracts were centrifuged and the supernatants were filtered through a $0.45 \mu \mathrm{m}$ membrane filter and collected. The extracts were decanted into small separator funnels. Upon addition of $1 \mathrm{~mL}$ of $20 \% \mathrm{NaCl}$ solution, a clear-cut separation of the two phases occurred and the presence of carotenoid pigments was evident as the upper petroleum ether layer was colored yellow, orange, pink or intense red. The absorbance spectra at $474 \mathrm{~nm}$ were recorded on a UV-VIS spectrophotometer (UV-1600PC Spectrophotometer, Mapada Instruments Co., Ltd, Shanghai, China) and calculated by using Equation 1, as follows:

$$
\mathrm{C}=\left(\mathrm{A} \times \mathrm{V} \times 10^{6}\right) / A_{1 \mathrm{~cm}}^{1 \%} * 100 * \mathrm{~m}
$$

Where, $\mathrm{C}=$ total concentration of carotenoids $(\mu \mathrm{g} / \mathrm{g}) ; \mathrm{A}=$ absorbance; $\mathrm{V}=$ volume $(\mathrm{mL}) ; \mathrm{m}=$ dry cell mass $(\mathrm{g}) ;{ }^{\prime} A_{1 \mathrm{~cm}}^{1 \%}=$ specific absorptivity [8], [9].

Determination of antioxidant activity: The free radical scavenging activity was measured by the 2-2-diphenyl-1-picrylhydrazyl (DPPH) method as described by Loo et al. (2008). Different dilutions of the carotenoid extracts $(1 \mathrm{ml})$ were added to $2 \mathrm{ml}$ of DPPH (5.9 $\mathrm{mg} / 100 \mathrm{ml}$ methanol) and allowed to react at room temperature for $30 \mathrm{~min}$. The absorbance of the mixtures was measured at $517 \mathrm{~nm}$, after 30 min of incubation in the dark. A control was prepared without sample or standard and measured immediately at $0 \mathrm{~min}$ - the lower the absorbance of the reaction mixture, the higher free radical scavenging activity. The percentage of the DPPH scavenging effect was calculated by using Equation 2, as follows: 
DPPH scavenging effect $(\%)=($ Acontrol - Asample $/$ Acontrol $) \times 100$

Where Acontrol is the absorbance of the control reaction containing all reagents except the compound tested. Asample is the absorbance of the test compound. The concentration of extract needed to scavenge $50 \%$ of DPPH free radicals was calculated from the graph-plotting inhibition percentage against extract concentration [7].

\section{RESULTS AND DISCUSSION}

The stock culture of R.glutinis R12 was kept at $-80^{\circ} \mathrm{C}$ and it was inoculated in YM broth medium for the investigation of morphology, physiology and biochemical characteristics. By a microscopic analyses of the yeast culture after $24 \mathrm{~h}$, the production of the spores and pseudohyphae were not observed. The reproduction is budding. The colonies with pink-red color, round and smooth were grown in the YM agar medium (Figure 1).

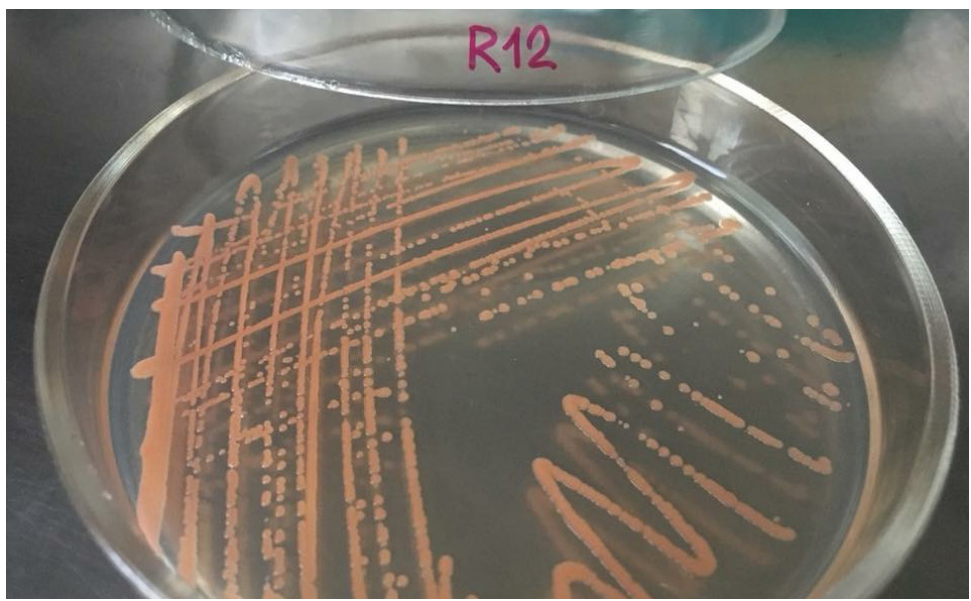

Figure 1. The colonies of R.glutinis R12 were grown in the YM agar.

Carbon and nitrogen assimilation is an important criteria in the taxonomy and identification of yeasts, which depends on organic carbon sources for their energy supply and growth, the carbohydrates being the sources of greater importance. R.glutinis R12 was assimilated mono- and disaccharides such as glucose, fructose, maltose mannose, respectively, also glycerol and ethyl alcohol and assimilated all nitrogen sources used in this study. But other sugars and sugar alcohols were not assimilated, expect ethanol (Table 1). It was previously reported that Rhodotorula glutinis did not assimilate carbon source such as melibiose, lactose, erythritol, starch, myoinositol and methanol and creatine as carbon source, and did not grow at $42^{\circ} \mathrm{C}$ [1].

Table 1. Physiological and Biochemical characteristics of R.glutinis R12

\begin{tabular}{|c|c|c|c|c|c|}
\hline Characteristics & R.glutinis & Characteristics & R.glutinis & Characteristics & R.glutinis \\
\hline Fermentation & - & Inulin & - & $25^{\circ} \mathrm{C}$ & + \\
\hline Glucose & + & Cellulose & - & $30^{\circ} \mathrm{C}$ & + \\
\hline Fructose & + & Glycerin & + & $37^{\circ} \mathrm{C}$ & + \\
\hline Lactose & - & Dulcitol & - & $42^{\circ} \mathrm{C}$ & - \\
\hline
\end{tabular}




\begin{tabular}{|c|c|c|c|c|c|}
\hline Maltose & + & Mannitol & - & Vitamin free & + \\
\hline Sucrose & + & Methanol & - & Urease & + \\
\hline Xylose & - & Ethanol & + & Starch formation & - \\
\hline Rhamnose & - & $\left(\mathrm{NH}_{4}\right)_{2} \mathrm{SO}_{4}$ & + & $50 \%$ - Glucose & - \\
\hline Melibiose & - & $\mathrm{KNO}_{3}$ & + & $60 \%$ - Glucose & - \\
\hline Mannose & + & $\mathrm{NaNO}_{3}$ & + & $0.01 \%$ cyclohex. & - \\
\hline Starch & - & $20^{\circ} \mathrm{C}$ & + & & \\
\hline
\end{tabular}

(-) Negative test, (+) Positive test

The yeast culture was inoculated in three different media (MS3, YM broth and Basal medium) and cultivated for 5 days (Figure 2). Stationary phase of all the cultures in the different culture media was obtained between
72 to 120 hours. R.glutinis has the ability to produce carotenoid pigments during the stationary phase [12]. Therefore, it was not necessary to incubate for more than $120 \mathrm{~h}$. The further assays were studied in those times.

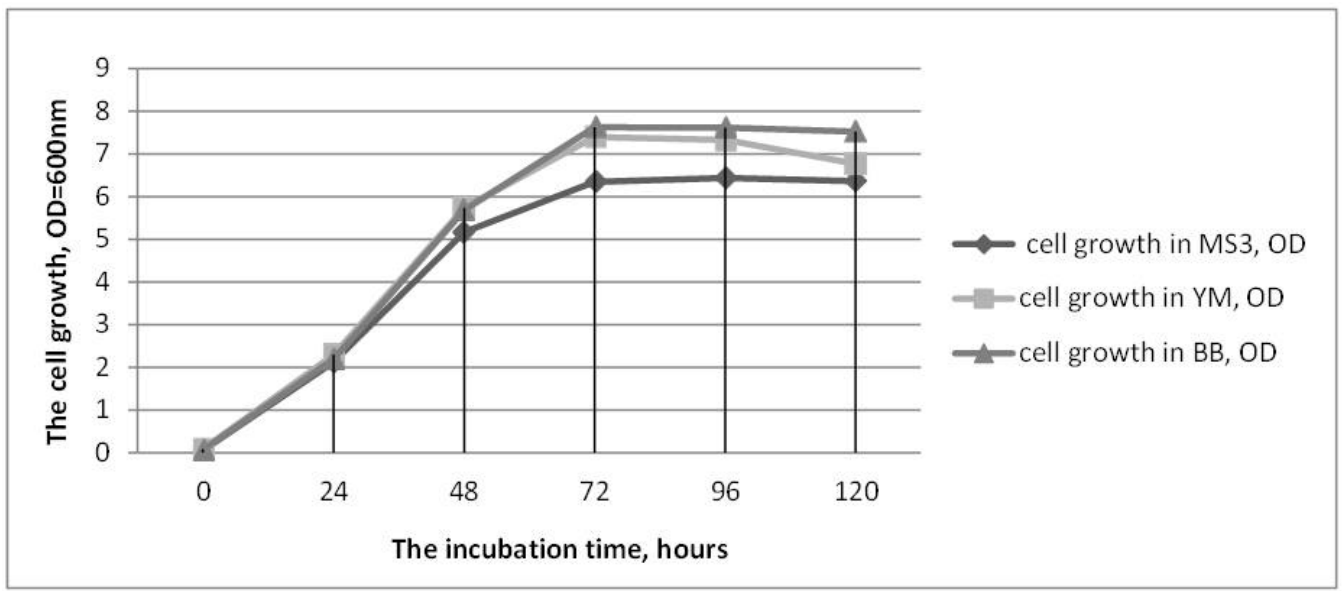

Figure 2. The cell growth of R.glutinis R12 during 5 days fermentation in different media

During the fermentation, the amount of biomass and total carotenoid of the strains were evaluated by dry cell weight and spectrophotometric methods respectively (Figure 3). The dried cell biomass and the carotenoid content in the produced extract fluctuated between $5.4 \pm 0.14-8.76 \pm 03 \mathrm{~g} / \mathrm{L}$ and $97.46 \mu \mathrm{g} / \mathrm{g}(0.7 \mathrm{mg} / \mathrm{L})-284.6 \mu \mathrm{g} / \mathrm{g}(2.49 \mathrm{mg} / \mathrm{L})$ respectively, depending on the culture medium and incubation time. The highest biomass yield $(8.76 \pm 03 \mathrm{~g} / \mathrm{L})$ and the carotenoid content $(284.6 \mu \mathrm{g} / \mathrm{g})$ were obtained from Basal medium culture after $120 \mathrm{~h}$. Many studies of carotenoids by strains of R.glutinis have been reported. Maximum yield $(5.95 \mathrm{mg} / \mathrm{L}$ of total carotenoids culture fluid, $630 \mu \mathrm{g} / \mathrm{g}$ dry cell weight) was obtained after a batch culture of $120 \mathrm{~h}$ in a substrate containing concentrated rectified grape must as the sole carbohydrate source [6]. The mutant of R.glutinis produced $\beta$-carotene by getting up to $2.2 \mathrm{mg}$ of carotenoids/ $\mathrm{L}$ in 72 $\mathrm{h}$ [4]. On the other hand, Turkan et al reported that carotenoid concentration obtained from R.glutinis strains was between 0.23 and 1.23 $\mathrm{mg} / \mathrm{L}$ [26].The results in this study obtained moderate value to compare other studies.

Carotenoid pigment has the ability to act as antioxidants and thus protect cells against photooxidation. The ability of carotenoids to quench singlet oxygen is well known and reactions with radical species have also been studied [10]. Antioxidant activities of extracts showed highest carotenoid content were studied by the DPPH radical scavenging method. The results are shown in Table 2. 


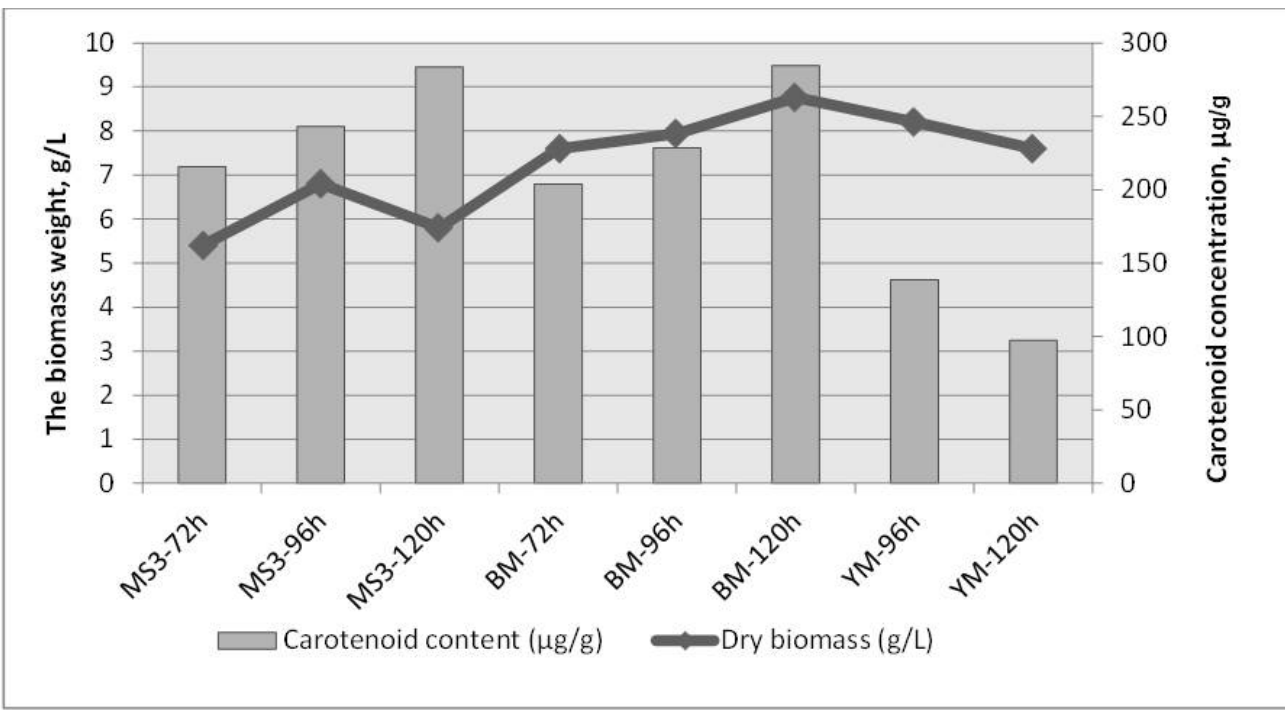

Figure 3. Carotenoid content and biomass yield of R.glutinis R12 in the different culture media and at different time.

Table 2. Antioxidant activity of carotenoid extracts from R.glutinis R12

\begin{tabular}{|l|c|c|c|}
\hline \multicolumn{1}{|c|}{ Cultivated media } & $\begin{array}{c}\text { Carotenoid extract } \\
\text { concentration, } \mu \mathrm{g} / \mathrm{ml}\end{array}$ & $\begin{array}{c}\text { DPPH radical scavenging } \\
\text { activity, } \%\end{array}$ & $\mathrm{IC}_{50}, \mu \mathrm{g} / \mathrm{ml}$ \\
\hline \multirow{3}{*}{ Basal medium } & 600 & $52.09 \pm 0.4$ & \\
& 300 & $42.29 \pm 0.48$ & $\mathbf{5 3 6 . 0 2}$ \\
& 150 & $30.28 \pm 1.06$ & \\
MS3 medium & 600 & $51.96 \pm 0.26$ & 568.75 \\
& 300 & $33.15 \pm 0.2$ & \\
\hline
\end{tabular}

mean $\pm S D(n=3), I C_{50}$ sample concentration required scavenging $50 \%$ of the DPPH radical, $\mu \mathrm{g} / \mathrm{ml}$

The maximum antioxidant characteristics of carotenoid by DPPH radical scavenging assays were achieved $52.09 \pm 0.4 \%\left(\mathrm{IC}_{50}=536.02\right)$ at the concentration of $600 \mu \mathrm{g} / \mathrm{ml}$ by pigmentation of R.glutinis R12. Michalowska and Stachowiak reported that highest percentage of DPPH scavenged radicals was recorded in pigment produced from Phaffia rhodozyma for an addition of $0.05 \%$ carotenoid extract $(94.58 \%)$

\section{CONCLUSIONS}

This study revealed that R.glutinis (R12) is able to produce up to $284.6 \mu \mathrm{g} / \mathrm{g}$ carotenoid pigments under $120 \mathrm{~h}$ cultivation in the Basal medium, and these pigments have a significant antioxidant effect. The maximum antioxidant
[21]. Pigmentation of Sporobolomyces sp. at a concentration of $100 \mu \mathrm{g} \mathrm{ml}-1$ exhibited $75.04 \%$ [18].

Further study needs to be done to improve the strain and it is possible to use the carotenoids extracted from strains of Rhodotorula glutinis in feed and foods as natural preservatives as well as colorants.

activity was $52.09 \pm 0.4 \%$ at a concentration of $600 \mu \mathrm{g} \mathrm{ml}^{-1}$ and sample concentration required scavenging $50 \%$ of the DPPH radical was $536.02 \mu \mathrm{g} \mathrm{ml}-1$. 
Acknowledgements: This research work was financially supported by the Mongolian Foundation for Science and Technology. The authors would like to thank the colleagues of Laboratory of Microbial Synthesis for their valuable assistance.

\section{REFERENCES}

[1] Barnett, J.A., Payne, R. W., Yarrow, D (1990). Yeasts: Characteristics and Identification. Cambridge University Press, Cambridge, pp.14-28.

[2] Baigalmaa, Ts., Ariunzaya, Ts., Oyunchimeg, P., Bayarmaa, G., (2012). Selection and characterization of Carotenoid producing yeasts from fruits in Mongolia. Documents of Department of Biology and Biotechnology, National University of Mongolia. № 374, pp. $99-104$.

[3] Berman. J., Zorrilla-López, U., Farré, G., Zhu, C., Sandmann, G., Twyman, R. M., Capell, T., Christou, P., (2015). Nutritionally important carotenoids as consumer products. Phytochem. Rev. 14:727-743.

[4] Bhosale and Grade, (2001). Manipulation of temperature and illumination conditions for enhanced b-carotene production by mutant 32 of Rhodotorula glutinis. Letters in Applied Microbiology, 34:349-353

[5] Britton. G., Liaaen Jensen, S., Pfander, H., (2004). Carotenoids Handbook: Carotenoids. (eds) Sestak Z Verlag, Birkhauser Basel, vol. 42(2), p. 18.

[6] Buzzini, P., Rubinstein, L., \& Martini, A., 2001, Production of yeast carotenoids by using agro-industrial byproducts. Agro-Food-Industry Hi-Tech 12, pp. 7-10.

[7] Chanda, S., Dave, R., (2009), In vitro models for antioxidant activity evaluation and some medicinal plants possessing antioxidant properties: an overview. Afr J Microbiol Res 3:981-996.

[8] Chumpolkulwong, N., Kakizono, T., Nagai, S., Nishio, N.,(1997). Increased astaxanthin production by Phaffiarhodozyma mutants isolated as resistant to diphenylamine. J. Ferment. Bioeng. 83:429-434.

[9] Dominguez-Bocanegra,A.R., Torres-Muñoz,J.A.,(2004),Astaxanthin hyperproduction by Phaffiarhodozyma (now Xanthophyllomycesdendrorhous) with raw coconut milk as sole source of energy. Appl. Microbiol. Biotechnol. 66:249-252.

[10] Edge, R., Macgarvey, D.J. and Truscott, T.G., (1997), The carotenoids as antioxidants: A review. Journal of Photochemistry and Photobiology, 41: 189-200.

[11] G,u Z., Chen, D., Han, Y., Chen, Z., Gu, F., (2008). Optimization of carotenoids extraction from Rhodobacteriasphaeroides. LWT - Food Sci.Technology, 41:10821088.

[12] Henriquez, V., Escobar, C., Galarza J., and Gimpel, J., (2016), Carotenoids in microalgae, Carotenoids in Nature, Springer International Publishing, pp. 219-237.

[13] Herniquez-Almanza, A., Julio Cesar Montanez, Miguel A. Aguilar-Gonzalez, Cristian Martınez-Avila, Raul Rodrıguez-Herrera, Cristobal N. Aguilara (2013). Rhodotorula glutinis as source of pigments and metabolites for food industry. Food Bioscience

[14] Hoog, G. S., De Guarro, J., Gene, J. \& Figueras, M. J. (2001). Atlas of Clinical Fungi, Second edition, December 1, Washington: ASM Pressp. ISBN 9070351439.

[15] Li. E., and Mira de Orduca R (2010), A rapid method for the determination of microbial biomass by dry weight using a moisture analyser with an infrared heating source and an analytical balance. Letters in Applied Microbiology, 50(3), pp. 283-288. 
[16] Loo, A.Y., Jain, K., Darah, I., (2008). Antioxidant activity of compounds isolated from the pyroligneous acid, Rhizophoraapiculata, Food Chem 107:1151-1160.

[17] Maldonade, I. R, Rodriguez Amaya D. B., Scamparini, A. R. P., (2007), Carotenoids of yeasts from Brazilian ecosystem. Food chemistry, vol 107, pp 145-150.

[18] Manimala, M. R. A. and Murugesan, R. (2014). In vitro antioxidant and antimicrobial activity of carotenoid pigment extracted from Sporobolomyces $s p$. isolated from natural source. Journal of Applied \& Natural Science. 6 (2): 649 - 653.

[19] Marova, I., Carnecka, M., Halienova, A., Certik, M., Dvorakova, T., \&, Haronikova, A. (2012). Use of several waste substrates for carotenoid-rich yeast biomass production, Journal of Environmental Management, 95, S338-S342.

[20] Medeiros, F., Alvas, F.G., Lisboa, C. R., Martinis, D., Burkert, C.A.V, Kalil, S.J. (2008),Ultrasonic waves and glass pearls: Anew method of extraction of $\beta$-galactosidada for use in laboratory. Quim. Nova 31:336-339.

[21] Michalowska and Stachowiak (2010). The antioxidant potential of carotenoid extract from phaffiarhodozyma.

[22] Pagmadulam, B., Tserendulam, D., Rentsenkhand, Ts., (2013), The study of yeast taxanomy, The proceeding of the Institute of Biology, Vol 29, pp. 46-49.

[23] Parichehr Hanachi and Farzaneh Sadat Naghavi, (2016), Evaluation of Antioxidant Activity of R.slooffiae, R.mucilaginosa Extracts. Electronic Physician (ISSN: 20085842), Volume 8, pp. 3110-3115.

[24] Roadjnakamolson, M., \& Suntornsuk, W,. (2010), Production of $\beta$-caroteneenriched rice bran using solid-state fermentation of Rhodotorulaglutinis, Journal of Microbiology and Biotechnology, 20(3), pp. 525-531.

[25] Tserendulam,Ts., Bayarlhagva, D., Badrakh, .B, and Dulamsuren, Ch., (2001), Some results of the experiments for the estimation of the growth dynamics and the carotenoid synthesis activity. The proceedings of the Institute of Biology. Vol 23, pp. 213-218.

[26] Turkan Mutlu Keceli, Zerrin Erginkaya, Esra Turkkan and Umit Kaya, (2013), Antioxidant and Antibacterial Effects of Carotenoids Extracted from Rhodotorula glutinis Strains. Asian Journal of Chemistry; Vol. 25, No. 1, pp. 42-46.

[27] Vachali, P., Bhosale, P., Bernstein, P.S., (2012). Microbial carotenoids from Fungi. Method in Molecular Biology (Method and Protocols). Vol 898, pp. 41 -59.

[28] Valduga, E., Valyrio, A., Tatsch, P. O., Treichel, H., Furigo, Jr. A., Luccio M. D., (2009), Optimization of the production of total carotenoids by Sporidiobolussalmonicolor (CBS 2636) using response surface technique. Food Bioprocess Tech. 2: 415-421.

[29] Valduga, E., Tatsch, P. O., Tiggemann, L., Treichel, H., Toniazzo, G., Zeni, J., Luccio, M. D., (2009), Carotenoids production: Microorganisms as source of natural dyes. Quim. Nova 32: pp. 2429-2436. 